\title{
SUMA QAMAÑA = EL BUEN CONVIVIR
}

\author{
Xavier Albó \\ Centro de Investigación y Promoción del Campesinado (CIPCA). Bolivia
}

\begin{abstract}
Resumen
Una de las principales expresiones con que actualmente se busca sintetizar el nuevo estilo de país que deseamos construir es "vivir bien", contrapuesto a "vivir mejor". Se ha introducido ahora incluso en el solemne Preámbulo de la Constitución promulgada en febrero 2009, donde enumera las virtudes que debería tener la nueva Bolivia - respeto, igualdad entre todos, solidaridad, armonía, equidad, etc.- y concluye: "donde predomine la búsqueda del vivir bien".
\end{abstract}

Palabras clave: Constitución, buen vivir, equidad.

\begin{abstract}
One of the main expressions currently seeks to synthesize the new style of country we want to build is "Living Well", as opposed to "Live Better". It has now been introduced even in the solemn Preamble to the Constitution promulgated in February 2009, where the virtues that should have the new Bolivia are listed -respect, equality among all, solidarity, harmony, equity, etc.- and concludes: "where preponderates the search for Living Well".
\end{abstract}

keywords: Constitution, living well, equality.

En el articulado, se lo reitera ya en aymara, suma qamaña, como uno de los grandes "principios ético-morales de la sociedad plural", junto con otros relativamente equivalentes en guaraní y quechua (art. 8).y lo encontramos de nuevo en el tema educativo (art. 80) y en el económico (art. 306, 313). ¿Qué está detrás de tal concepto? Lo exploraré de una manera gradual y cada vez más expansiva, primero en términos puramente lingüísticos y finalmente lo ampliaré a niveles más amplio en otros dos ámbitos: la lógica común a muchos pueblos indígena originarios, contrapuesta a la de las sociedades y poderes dominantes; 
y su plasmación como parte de la utopía de país, presente en la nueva Constitución Política Boliviana.

\section{LA BASE LINGÜÍSTICA AYMARA}

A veces las traducciones son traicioneras: traduttore traditore, dicen los italianos. Algo de ello ocurre con la expresión 'vivir bien' si no se la contextualiza en la lengua y cultura dentro de la que fue acuñada la fórmula original suma qamaña. Repasemos pues primero su sentido originario tanto en la lengua como en la cultura aymara ${ }^{1}$. Será bueno entenderlo en su plenitud, para aplicarlo después correctamente. Analicemos y gocemos ante todo estas dos palabras:

\section{QAMAÑA}

Qamaña es 'habitar, vivir [en determinado lugar o medio], morar, radicar' (to dwell, en inglés) y qamasiña, 'vivir con alguien'. Qamaña es también el nombre que se da al lugar abrigado y protegido de los vientos, construido con un semicírculo de piedras, para que, desde allí los pastores, mientras descansan, cuiden a sus rebaños. Es decir, qamaña, desde sus diversos ángulos, es vivir, morar, descansar, cobijarse y cuidar a otros. En su segundo uso, insinúa también la convivencia con la naturaleza, con la Madre Tierra Pacha Mama, aunque sin explicitarlo. Como nos enseñan los lingüistas, la raíz conceptual es qama-, a la que se van añadiendo diversos sufijos para añadirle nuevos matices, como por ejemplo -ña, que lo verbaliza. Nos ayudará por tanto ver algunos otros términos directamente asociados:

Qama-wi (con el localizador -wi) es 'morada', pero qamäwi (nominalizador de la acción verbal) es, de una forma muy significativa, la 'reunión de personas que acostumbran juntarse para conversar o pasar agradablemente el tiempo'. Qamasa, además del gerundio 'viviendo, conviviendo', es 'el carácter, el modo de ser' y también 'el valor, la audacia, el ánimo, el coraje'. Se dice también que tal o cual lugar, o incluso el sol, una wak'a o un cerro sagrado tienen mucho qamasa, en ese sentido y el más genérico, de mucha 'energía' y, por tanto, se hacen gestos y rituales para llenarse de esa energía. Qamasa es, por tanto, la energía y fuerza vital para vivir y compartir con otros'. Esta es quizás la relación más explícita entre la raíz qama- como algo que está de manera muy fuerte y viva en la Pacha Mama y nosotros que la habitamos y hacemos de ella nuestra morada.

1. Me baso sobre todo en Félix Layme (2004), con quien he hecho además varias consultas personales. 
La manera más común para decir en aymara para decir que alguien es 'rico' es Qamiri. Y viceversa, para hablar en aymara de gente rica, burguesa, prepotente, etc. muchos, aymaras o no, suelen recurrir a ese término en plural: qamirinaka. Pero a la luz de lo anterior, no resulta tan claro que este sea el sentido original, aunque aparezca ya en los primeros diccionarios. La connotación más profunda no sería la de un ricacho que vive de una manera lujosa y prepotente a costa de los otros.

Esto se nos acaba de aclarar al contrastar la manera de expresar regularmente que alguien es 'pobre', es decir, lo contrario de 'rico'. La palabra que tanto quechuas como aymaras prefieren siempre para decir pobre, mendigo, es waxcha (o waqcha, en quechua), que en rigor significa 'huérfano, abandonado'. Es decir, lo que se subraya ante todo es la falta de seguridad y del calor de la de convivencia en su vida, más que la carencia de bienes materiales ${ }^{2}$.

Todo este abanico de sentidos de qamaña, con una mayor referencia a la convivencia social y también ecológica, son más ricos que los de jaka-ña, que es también vivir y vida, pero sólo en el sentido de estar vivo, contrapuesto a estar muerto y a muerte (to live, en inglés). Por eso, cuando en el mundo andino, y en tantos otros pueblos indígenas originarios, se afirma que las suyas son culturas para la vida, no se refieren sólo a este hecho físico de vivir sino también a todo este conjunto de relaciones sociales con un ambiente de acogida. Por eso se habla además de "cuidar" y "criar" la vida, como algo que hacemos juntos, en familia.

En el más antiguo y clásico diccionario aymara de Bertonio (1612), se usa jakaña para los sentidos más simples de "vivir". Pero para "vivir en paz" y "vivir a gusto" recurre a qamaña: muxsaki qamaña 'vivir no más dulcemente'.

\section{SUMA QAMAÑA}

Dos diccionarios recientes (De Lucca 1987, Layme 1994) describen suma como "bonito, hermoso, agradable, bueno, amable", pero también, "precioso, excelente, acabado, perfecto". Tiene también, por tanto, un sentido de plenitud que no se le da en castellano. Y suma jaqi es 'buena gente, bondadoso, generoso, que tiene buena voluntad a otro".

¿Por qué no quieren hablar tanto de vivir mejor? En su concepción, los pueblos originarios (al menos los andinos) no lo ven necesario precisamente

2. En la casa parroquial de Qurpa acudía con frecuencia un célebre viejito pidiendo algo y, pese a sus muchos años, decía en castellano: 'es que soy huerfanito'. Al cura español le sorprendía que apelara a sus padres muertos muchísimo tiempo atrás. Pero en ese contexto aymara resulkta más bien iluminador sobre qué hace a alguien rico o pobre: la capacidad de vivir acogido y compartiendo con los demás. 
porque suma (o sumaq en quechua) ya puede incluir en sí mismo "el mayor grado posible". Por otra parte, los aymaras que han reflexionado más en este asunto se resisten a decir "mejor" porque se entiende demasiadas veces como que un individuo o grupo vive y está mejor que otros y a costa de los otros. Suma qamasiña es [con] vivir bien, no unos mejor que otros y a costa de otros.

Eso último es lo que hace q'ara a alguien, más que el color de la piel ${ }^{3}$, pues en realidad q'ara significa desnudo, pelado, es decir el que carece de algo fundamental. Equivale a "incivilizado", por no cumplir la regla y objetivo fundamental de la convivencia. Lo contrario de suma qamasiña 'convivir con bondad y generosidad' sería q'araru tukuña, hacerse pelado, incivilizado, por no tener algo fundamental. Obviamente, si hay formas de convivir que son buenas y generosas, también puede haber esas otras que no lo son y el ideal es reforzar las primeras.

Por tanto, al decir sólo "bien", en este sentido de suma(q) y en el contexto de qamaña, ya se incorpora que todo el conjunto social es del todo bueno. Algo mucho mejor que ver simplemente que algunos están mucho mejor que los demás. Si mejoramos tiene que ser, en lo posible, todos a una para estrechar esos lazos de convivencia.

En un reciente taller del Viceministerio de Planificación sobre el objetivo central del desarrollo, un aymara comentó: "Es que suma qamaña en realidad no es 'vivir bien' sino 'el saber convivir y apoyarnos los unos a los otros'". Y el suma qamiri pasa a ser el que vive y convive bien porque es acogido por todos y sabe acoger y colaborar a todos con lo poco o mucho que tiene. En cierta manera ya no puede darse individualmente sino sólo en y con un grupo social mayor.

Estas aclaraciones nos permiten penetrar un poquito en esas percepciones de los pueblos originarios, que no suelen tenerse tan en cuenta en planificaciones y propuestas de desarrollo. Y no está mal que también en la Constitución se haya abierto camino a eso de buscar el suma qamaña, el "bien vivir".

\section{LA PRÁCTICA COTIDIANA AYMARA}

¿Hasta qué punto esto es realidad en la vida cotidiana aymara? Que lo anterior tiene algo de utopía es evidente; y más utópico es todavía su lugar preferencial en el conjunto de la nueva Constitución. El doble nivel interpretativo que ya tiene el término qamiri, como 'el que comparte generosamente con todos'

3. Actualmente muchos interpretan este término en un sentido racial, pero tal sentido sería sólo figurado y se aplica también a aymaras que ya no se comportan con esas normas básicas de la convivencia. A veces, al preguntar por qué a uno muy rico le llaman q'ara, cyando en realidad no le falta nada, me han respondido: "no tiene nada suyo, fruto de su trabajo", "palabra". Muchos piensan que este término es más bien racial 
y como 'rico' en nuestro sentido occidental, ya nos muestra cierta pugna entre el ideal y la realidad cotidiana. Pero ésta tiene también una serie de elementos que nos muestran esta otra lógica más convivial.

Lo voy a mostrar primero en las relaciones humanas cotidianas, expresadas en la raíz tumpasiña; y después, con mayor detalle, al nivel más comunal del camino (thakhi) por el que todos nos vamos realizando socialmente a lo largo de la vida a un paso relativamente acompasado y compartido dentro del tejido social comunario.

\section{TUMPASIÑA}

En 2005, en una charla a un grupo de visitantes de otros países el más adelante canciller David Choquehuanca usó como una de sus palabras-conceptos clave tumpa-, definido como 'el control mutuo entre todos'. Pero hay que aclarar de qué tipo de "control" se trata. Las formas más usadas son en, realidad las relacionadas con el verbo tumpasiña, que al pasarlo al castellano la gente suele traducir como 'echarse de menos'. Veamos como lo describió un amigo y compañero mío, "Pepe H", que pasó treinta años conviviendo con las comunidades Aymara Altiplánicas de Jesús y San Andrés de Machaqua":

"La lengua aymara es una "lengua de ángeles". Tiene un verbo tumpasiniña, que expresa maravillosamente este sentimiento de totalidad que el Altiplano ejerce sobre sus moradores. Se puede traducir por: "Ir a visitar, ir a ver, ir a percatarse ocular y personalmente de alguien o de algo propio o considerado como propio, y por tanto muy querido, muy amado, muy apreciado por uno. Un ir a echarse de menos". Sentimiento que no se satisface una sola vez, sino que reiterativamente surge en el corazón como algo ineludible. La inmensidad del Altiplano nos hace sentir minúsculos en medio de él, por eso cuando de pronto en nuestra vida sumergida en esta inmensidad, se nos acerca un campesino y nos dice: "he venido a echarte de menos" se experimenta como un "desvelamiento" por no decir una "revelación" de la profundidad del Altiplano. ¡Uno se pensaba y se sentía pequeño, desconocido, extranjero... y de pronto le hacen notar que alguien en su corazón se ha apropiado de uno!

Ir a echarse de menos, no es ir a controlar, a vigilar, a pedir cuentas, a examinar, a juzgar... pues todas esas cosas se pueden hacer por terceras personas o con otros medios impersonales. No se va a echarse de menos por utilidad o en busca de seguridades personales, diría que se va porque sí, se va porque se ama."

He aquí algunos otros ejemplos cotidianos recogidos por el mismo Pepe H:

4. Esta cita y las siguientes provienen de Albó, ed. 2008: 181 y 174-3. El texto completo de este y otros muchos escritos de José Fernández de Henestrosa está en el CD adjunto al libro. 
"Una reunión de mujeres... Si son jóvenes y están embarazadas, se sentirán protegidas, rivilegiadas, aconsejadas y acompañadas, por sus compañeras que saben lo que les espera. Si están con su wawas de meses, crearán en su entorno un círculo protector que va desde 'cargarlas' a sus espaldas mientras duermen, hasta el darles de mamar las veces que convenga si es que la wawa se siente insegura...

El trato que la gente tiene con los borrachos cuando irrumpen en una reunión o en la misma capilla. Un extraño respeto y condescendencia, lejos de cualquier juicio moral o repulsa condenatoria, por más que entorpezcan la buena marcha de la reunión. Siempre habrá quien sabe hacerse cargo de él tratándolo con delicadeza. Cómo acogen al hijo o a la hija que ha ido a trabajar a la ciudad y después de largo tiempo viene a 'echarse de menos' de ellos. Al despedirlos les llenaran de todo, pues lo poco que tienen se lo dan.

Los dirigentes de las comunidades durante su año de autoridad dedican todo su tiempo al servicio de su comunidad correteando de un lugar a otro para lograr que mejoren su escuelas o colegios, se atienda bien en salud, arreglen los caminos, sus comunarios se reconcilien cuando hay peleas, los visitantes se sientan bien recibidos..."

En esta misma línea entran otros muchos elementos clave de la vida cotidiana aymara, que tienen todos ellos numerosas prácticas de reciprocidad (ayni, waqi, umaraqa...) a partir del intercambio de dones y servicios, que llenan el trabajo agrícola, todas las fiestas y celebraciones con sus pasantes, el servicio de "pasar" también por cargos comunales, etc. Por esa vía las redes entre familias, dentro y más allá de la comunidad, se va haciendo cada vez más tupidas por esos intercambios y nuevas alianzas entre parientes, padrinos, compadres y ahijados...

De todo ello, el ejemplo que mejor nos introduce en el segundo nivel, más estructurado y organizado en torno a toda la comunidad e incluso más allá es el de los cargos comunales, en el que me detendré en el siguiente acápite.

\section{EL THAKHI ${ }^{5}$ O CAMINO COMUNAL}

Tanto entre los Aymaras como en otros pueblos Andinos, toda la vida de cada individuo es concebida como caminar, en una creciente madurez expresada sobre todo en el mayor servicio a la comunidad. Este proceso por el que de una $\mathrm{u}$ otra manera y a ritmos distintos todos pasan, en aymara se llama thakhi 'camino'.

Se trata por lo general de servicios crecientemente onerosos hasta llegar al rango de "pasado", es decir hasta haber cumplido el cargo de máxima res-

5. Ver Albó (1993) y Ticona y Albó (1997: cap. 3). 
ponsabilidad. Con el cumplimiento sucesivo de determinados servicios, la persona o pareja que pasa por ellos va creciendo en responsabilidad y a la vez en reconocimiento por parte de la comunidad, por la manera que preocupa y se echa de menos a la gente a la que está sirviendo. Al acabar el período del cargo (actualmente suele ser un año) quienes lohayan satisfecho reciben el reconocimiento agradecido de toda la comunidad y muy particularmente de sus ahijados y unos y otros serán también bendecidos por todos los seres protectores de la comunidad.

De un lugar a otro y de una época a la otra puede haber muchas variantes en la manera que este esquema se realiza. Pero el esquema global es el que acabo de señalar, al que, sin poder entrar en mucho detalle, añado algunos otros rasgos más comunes y significativos para nuestro tema del suma qamaña.

Ya ocurren ciertas responsabilidades desde la niñez y la juventud. Pero el primer gran hito dentro de ese camino es el momento en que se forma la pareja, y los dos cónyuges pasan por tanto a ser realmente 'persona' $(\mathrm{jaqi})^{6}$. Ese mismo proceso matrimonial, que tiene a su vez sus propias etapas de creciente vinculación y compromiso de los dos con la comunidad, se llama jaqichasiña 'hacerse persona'. A través de sus padres, es la comunidad la que entonces les da tierra sea cual fuera el estatus jurídico de esas parcelas, según el lugar. Entonces, por reciprocidad, la pareja empieza también a ocupar diversos cargos de servicio a la comunidad, alterando tareas más civiles (como ser apoyos para la escuela o secretario de actas) y otras más festivas y hasta sacrales, como el desempeño de determinadas funciones en las fiestas religiosas (jefe de un conjunto de baile, por ejemplo). Estas responsabilidades recaen siempre sobre la pareja, aunque con diversas funciones para el varón o la mujer, ella siempre más ocupada preparar, acompañada por otras mujeres, las comidas con se va invitando a los participantes.

En la manera en que se va nombrando a la gente para esos cargos, entra otro elemento: el muyu (rotación) o mit’a (turno). Esos turnos siguen más o menos el orden de las diversas sayañas, es decir de las terrenos más asociadas al lugar donde se asienta la vivienda principal de la familia parcelas. Hay una clara relación entre el acceso a la vida social, la responsabilidad como autoridades y el acceso al territorio sobre el que se vive (qamaña) y cada grupo familiar establece su morada y terrenos. Existe además un ayni implícito de

6. El diccionario colonial de Bertonio (1612) añade otra interesante expansión del sentido de jaqi: "un par de cosas compañeras", por ejemplo, "tres, cuatro jaqi de zapatos": Todo ello nos lleva a otro tema, el de la unidad y complementariedad equilibrada del chachawarmi 'marido-mujer' y, de ahí, la concepción dual, casi sexuada, de toda la sociedad y el cosmos. 
reciprocidad entre cumplir estos cargos (aparte otras obligaciones como trabajos y cuotas para determinados gastos) y que la comunidad les respete su derecho a mantener sus terrenos que, en el fondo, son parte del territorio comunal, incluso cuando en algunos lugares existan ya a veces títulos individuales de la oficina de reforma agraria. Si cumplen esas sus obligaciones, califican también para que la comunidad les proteja y les administre justicia cuando tengan algún pleito interno.

Pero no se trata de unos turnos mecánicos, como las rueditas y manecillas de los viejos relojes, sino de cierta rotación que va clasificando a la gente que hayan alcanzado ya cierto nivel y después, dentro de él, algunos se van ofreciendo como voluntarios y la asamblea a su vez puede escoger y preferir a unos para ciertos cargos y a otros para otros, según su capacidad.

Turno, voluntad y capacidad se combinan, aunque no siempre con la misma dosificación. Aunque teóricamente todos deben recorrer todo el camino y sólo una vez, no siempre es así, dependiendo del tamaño de cada comunidad, de las habilidades reales de cada uno y también de cómo otros comunarios les ayuden en recursos y apoyos prácticos para desempeñar ese rol que les toca cumplir.

Aunque ya no tanto como en el pasado, los propios interesados se van anotando en la lista o "fila" para cumplir determinados cargos (o rangos de cargos), sobre todo los principales.

En algunos lugares de Jesús de Machaqa hay una ceremonia llamada thakhi chhipiña, que quiere decir 'roturar el camino', el cual suele coincidir a su vez con la época anual en que se realiza el yapu laki o distribución (en realidad, reconocimiento) de los nuevos terrenos que corresponden a cada familia en un área de propiedad colectiva llamada aynuqa y que volverán a ser roturados después de diez o más años de descanso. Roturar los nuevos cultivos de papa coincide con roturar el camino de las nuevas parejas que recién lo inician. En cierto momento clave las personas -varones en un lado, mujeres en el otro- se van colocando a diversos niveles según lo que vayan avanzado dentro del camino chico (jisk'a thakhi), con los primeros cargos (más pesados pero aún poco prestigiosos); del camino intermedio (taypi thakhi); o del camino grande (jach'a thakhi), donde están los cargos de mayor responsabilidad cuyo cumplimiento trae también un mayor reconocimiento y prestigio. Quien quiera entrar en determinado cargo se acerca a los mallkus o autoridades salientes del camino grande y les ofrece el "cariño" de unas botellitas de trago diciéndoles "Yo quiero ocupar ese trago, ¿Me podrían ayudar?" Entonces averiguan después de cuántos años le tocará y con ello ya entran en la "fila", dentro de la que van avanzando año tras año, hasta que ocupan ya el cargo de mallku. Este es el otro gran hito. 
Cuando entra a este máximo nivel, uno de los primeros actos de la nueva pareja mallku se llama la uywara o uywthapi (lit. 'juntar el ganado') consistente en una gran comida en que se invita a toda la comunidad. Momentos similares pero no tan concurridos ni onerosos irán ocurriendo a lo largo del año, por ejemplo, en determinadas celebraciones y rituales o para invitar a su "rebaño" cuando concurra a determinados trabajos comunales.

Sigue después un año sumamente activo en que, como señalaba Pepe $H$, el mallku y su esposa mallku tayka 'madre malku' corretean de un sitio al otro "echándose de menos" a todo su "rebaño" de comunarios para servirles. Tener un cargo es, realmente tener una carga pesada de la que no salen enriquecidos sino con los bolsillos vacíos y cargados de deudas de ayni que en el futuro deberán devolver a quienes les han estado ayudando en ese año clave de su camino. Por eso un elemento clave en la indumentaria del tata mallku y su mallku tayka es el bulto ( $\left.q^{\prime} i p i\right)$ pesado que cargan en la espalda. La gente le critica si ese bulto no es pesado, pues debe significar que los dos cargan la responsabilidad por toda la comunidad. Un cargo es una carga, no un lucro. En algunas zonas de Oruro he visto incluso que en ese bulto llevan siempre plantas y hasta algunas flores como lana blanquecina que representan las nubes cargadas de lluvia que, gracias a ese su esfuerzo, caerá sobre todo la comunidad para bendecir su esfuerzo.

Transcurrido el año de servicio viene la gran ceremonia de cambio de autoridades. Se juntan los viejos y los entrantes cada uno con sus acompañantes y, en el contorno, otros comunarios, con sus pututus (cuernos-cornetas) que van sonando con júbilo. A los cesantes se los ve alegres. A los entrantes, serios si no tristes. En un momento dato, los primeros se quitan su ropa de autoridad y a los nuevos se la van poniendo. Éstos pasan entonces por diversas ceremonias rituales, mientras que los cesantes entran en el rango máximo de "pasados" y empiezan la gran fiesta. Sus ahijados y amigos llegan con bandas de música y cargados de pillus o grande collares y sombreros de panes y fruta y se los van colocando por todo el cuerpo hasta que casi ni se les ve. Y así empiezan a bailar con su acompañamiento dando vueltas por la plaza. De vez en cuando, descansan, les recogen todos esa ronda de pillus y otros le ponen más y más.

Algo semejante ocurre a nivel intercomunal y al de toda la marka, formada por decenas de comunidades y actualmente, en muchos casos, reconocida además como un municipio.

Estas y otras muchas prácticas muestran una lógica distinta, persistente sobre todo en las comunidades rurales. En ellas, como se habrá podido observarse esa manera de buen convivir va rebalsando de la esfera familiar a la 
comunal y más allá y no es sólo una cuestión social sino también política, ritual-sacral y hasta cósmica.

El análisis de otras importantes celebraciones anuales nos acabaría de mostrar la fuerza de esa visión y enfoque holístico. Resalta en ello, la celebración de Todosantos, que en realidad es el gran encuentro anual con los difuntos, que ya están en la otra forma de vida más allá del "lindero de la muerte" (jiwa qurpa) traspasado el cual se avanza al siguiente gran hito dentro del thakhi. Se celebra cabalmente cuando empieza la época de las lluvias, que nos traen los muertos y se quedan conviviendo con nosotros hasta la Pascua, cuando acaban las lluvias. Por eso tanto al principio de ese período, además de los ritos de bienvenida que se les da en las casas con finados recientes, hay una gran celebración familiar/comunal en los cementerios, de nuevo con gran abundancia de panes, frutas y bebida. Ahí se reúnen de nuevo todos para despedirlos el Jueves Santo. Por algo será que la raíz jiwa, además de 'muerte' entra también el el término jiwaki 'lindo, bonito' y hasta en jiwasa el 'nosotros incluso': tú y yo, nosotros y vosotros juntos.

Pero no olvidemos tampoco que estas comunidades aymaras tampoco son la utopía hecha realidad. Son distintos, conflictivos y dialécticos como todos los humanos. Todo ese sueño de una plena convivencia sigue siempre en pugna con otras realidades cotidianas más prosaicas, llenas de chismes y envidias y a veces incluso violentas. En 1975 escribí un texto que titulé "La paradoja aymara, solidaridad y faccionalismo", que repasé y reescribí de nuevo en 1986 con el título "Los desafíos de la solidaridad aymara" y de nuevo en 2002, en medio de nuevos conflictos como los de los ayllus Laymi y Qaqachaka, que dejaron unos 80 muertos, y nuevas esperanzas, como las que han llevado al aymara Evo al gobierno y, con él, han generado una nueva Constitución, dentro de la que se expresa también el ideal y la esperanza de que se pueda generalizar para todos el suma qamaña. Veamos pues qué tal podríamos avanzar más allá de esas comunidades rurales aymaras.

\section{MÁS ALLÁ DEL MUNDO AYMARA Y RURAL}

Ciertos elementos como los aquí señalados pueden reencontrarse también en las ciudades, dentro de determinados gremios ocupacionales, fraternidades de fiestas o en determinados barrios, aunque en ese contexto urbano, ya no participan todos sino sólo los que tienen más recursos y poder por lo que se enfatiza más el lucro, el poder real y el prestigio individual, por encima del servicio y la posibilidad de que todos vayan avanzando más a la par, dentro de la lógica del suma qamaña. 
No hay tampoco diferencias muy notables entre comunidades de habla aymara o quechua, cuando se encuentran en circunstancias socioeconómicas semejantes, pues en realidad la lengua no es la que cambia su cultura andina básicamente común. De todos la expresión aymara suma qamaña permite mayores connotaciones semánticas que su versión quichua/quechua sumak/sumaq kawsay, introducida también en la nueva Constitución ecuatoriana, pues desde una perspectiva puramente lingüística kawsay se asemeja más al jakaña aymara ${ }^{7}$.

También en otros pueblos indígena originarios hay concepciones semejantes aunque se expresen a través de otros conceptos. Aunque los ejemplos podrían multiplicarse en casi todos estos pueblos, tanto en Bolivia como en otros países, me limitaré a esbozar el caso de las comunidades guaraní del Chaco, en las antípodas ecológicas y culturales del mundo andino, por ser el otro caso más citado en el art. 8 de la nueva Constitución boliviana.

\section{EL SUEÑO GUARANÍ}

Los guaraní hablan sobre todo del ñande reko 'nuestro modo de proceder' en el que juegan también un rol fundamental tanto las relaciones de reciprocidad y el poder compartir la caza, pesca, comida y bebida cuando la hay en abundancia como la relación de todo ello con el territorio, visto ya no como "Madre Tierra" pero sí como "el lugar y el medio en que se dan las condiciones de posibilidad del modo de ser guaraní" . En cambio allí no hay nada parecido al elaborado sistema de autoridades ni al camino de cargos propio del mundo andino.

La principal expresión del buen convivir guaraní es seguramente el arete, su fiesta central a la que ahora, en castellano. llaman también Carnaval y que se celebra sólo en los años con buena producción. Ante todo festeja la cosecha del maíz. Con él preparan sus buenas tinajas de chicha que todos comparten con alegría hasta que se acabe, mientras bailan en rondas y celebran

7. El art. 8 de la Constitución boliviana señala también el qhapaq ñan que literalmente significa el 'camino señorial' pero interpretado por los constituyentes como 'vida noble'. Nótese que el término qhapaq era al parecer el título que tenían las autoridades pukina y pasó inicialmente al quechua con los sentidos de 'real, noble, principal, sagrado'. Pero en el lenguaje cotidiano actual significa sobre todo 'rico, adinerado, acaudalado', como el aymara qamiri aunque, a diferencia de éste, el término quechua no tiene ninguna relación con 'vivir, morar'. Ver Lira (1941/1982). En cambio el célebre ama qhilla, ama llulla, ama suwa incluido ya en la Constitución ecuatoriana de 1988 y ahora en la boliviana de 2009, proviene de los Comentarios reales del Inca Garcilaso de la Vega. Pero los alcances de su uso por parte del poderoso estado inca o a niveles más locales y cotidianos sigue siendo objeto de debate

8. Medina (2001b: 63), interpretando a Melià. 
también el reencuentro con los aña los muertos (representados por jóvenes adecuadamente ataviados con máscaras) que salen del bosque para unirse a la alegría de todos.

En términos de utopía, hay que resaltar también el mito (y las migraciones históricas) en busca de la "tierra sin mal" (ivi maräei), bella, resplandeciente, húmeda y fértil, en la que todos trabajan, a veces juntos (motirö), y en la que todos comparten los frutos de ese trabajo y la gran fiesta con chicha abundante (Melià 1987, 1988).

En CIPCA tuvimos allí una experiencia aleccionadora. Nuestro primer objetivo era apoyar la liberación económica de aquellas comunidades frente a su fuerte dependencia de la agroindustria cruceña a la que acudían anualmente varios meses durante la zafra cañera, bajo la coacción de una deuda permanente, aparte de la misma vulnerabilidad sus territorios subutilizados ante el agresivo avance de la agroindustria hacia el sur. Para ello pensamos que el fuerte el sentido comunitario allí tan fuerte podría enfocarse en nuevas actividades agrícolas y ganaderas que complementaran la autosubsistencia, abastecida por sus chacos familiares, con producción en común más orientada al mercado, en las que se llamaron "comunidades de trabajo", pronto expandidas en bastantes lugares. Sin embargo, llegado el momento de la cosecha de esa parte en común, muchas veces los economistas debieron reformular sus cálculos iniciales de réditos monetarios, porque el primer interés de los participantes no era vender el producto, como se había previsto, sino compartir lo más posible con todos los comunarios, sobre todo si se trataba de maíz. Sólo después de quedar todos bien satisfechos el saldo podía llegar al mercado.

\section{TEORIZANDO MÁS ALLÁ}

La persistencia de este enfoque en tantos pueblos ha llevado a muchos teóricos y hasta filósofos a cuestionar desde ahí las generalizaciones etnocéntricas que suelen hacerse desde el Primer Mundo. Desarrollar todo ello exigiría otras ponencias y libros. Me limitaré, por tanto, a puntear apenas algunas pistas.

Dentro de Bolivia quien ha hecho una mayor esfuerzo para sistematizar ideas como las aquí expuestas y enmarcarlas en una reflexión teórica más amplia ha sido Javier Medina, bien acompañado por otros aymaras como Simón Yampara y Mario Torrez. Ha explorado también la aplicación práctica de su perspectiva, sobre todo en el nuevo contexto creado a partir de la Ley de Participación Popular (1994) y su reconstrucción y fortalecimiento del nivel municipal, particularmente en las áreas rurales donde éste era antes sólo una ficción por su falta de recursos. 
Dentro de las numerosas publicaciones de Medina, que apuntan a esa mayor teorización y generalización, aquí llamaré la atención sobre su trilogía más reciente, publicada con apoyo de la GTZ y su proyecto PADEP para apoyar la gestión participativa municipal. Son: La comprensión indígena de la Buena Vida (2001a), que enlaza la experiencia aymara el con un marco teórico más amplio; el Ñande teko (2001b), sobre la experiencia guaraní; y La vía municipal hacia la vida nueva (2002) en que recoge y busca insumos para incorporar esos enfoques a la Estrategia Bolivia para la Reducción de la Pobreza: Presenta los principios más inclusivos y holísticos de los pueblos indígenas y también de diversos teóricos de todas las latitudes y los va contrastando con el enfoque mucho más economicista y diseccionador de los modelos dominantes de desarrollo y planificación. Aunque esos textos a veces se suben a un lenguaje demasiado esotérico, son quizás por ahora el sumario más estimulante para comprender las múltiples facetas del suma qamaña a un nivel más general.

Me limitaré a enunciar la lista de criterios sugeridos por Medina para acercarnos a la Bolivia "posible y deseable":

Una sociedad convivial

Una sociedad de frugalidad de vida y calidad de vida

Una sociedad de alta sinergia

Una sociedad de baja entropía

Una sociedad del equilibrio

Una sociedad eco-simbiótica con su espacio

Una sociedad de redes y flujos dinámicos

Una sociedad de democracias locales directas

No es tampoco casual que poco después, en 2003, Medina publicara también con el mismo apoyo de la GTZ y PADEP tres gruesos volúmenes con las principales aportes de Dominique Temple (2003), seguramente el teórico francés que más ha reflexionado y avanzado a partir del libro pionero de Marcel Mauss (1925) Ensayo sobre el don, y sin duda el que mayores lazos ha creado con los pensadores aymaras contemporáneos.

No es algo tan único. En el fondo la Declaración de la UNESCO (2001) sobre la diversidad cultural, como fuente principal de nuestro crecimiento en humanidad, y la necesidad de subordinar el desarrollo económico al desarrollo humano y cultural de cada pueblo, se mueve también en esa misma óptica. Lo mismo ocurre con los exitosos esfuerzos de Amartya Sen para desterrar de una vez aquel falaz promedio de la "renta per capita" y sustituirlo por el índice de desarrollo humano y otros complementarios. Y las nuevas corrientes 
sobre desarrollo sostenible, el ecodesarrollo y la protección del medio ambiente van en la misma dirección, de modo que quienes antes despreciaban la típica reverencia y cariño de los pueblos originarios por la Madre Tierra, con la que hay que realizar convites y practicar también la reciprocidad, ahora se sienten rebasados por estos nuevos enfoques, más cercanos a los de aquellos pueblos "primitivos".

Visto desde otra perspectiva, muchas de esas recientes innovaciones no hacen más que retornarnos a nuestras fuentes originarias. ¿ No hay mucho del suma qamaña, por ejemplo, en el saludo hebraico y bíblico shalom, que significa paz, en sus diversas acepciones tanto individuales como colectivas e internacionales y también bienestar y retorno al equilibrio, a la justicia y la igualdad integral?

\section{LA CONSTITUCIÓN POLÍTICA BOLIVIA 2009}

Para cerrar nuestro periplo, volvamos a nuestra nueva Constitución para ver en qué contextos desarrolla su manejo del suma qamaña. En todos ellos se añaden largas glosas en conceptos más occidentales:

Cuando lo señala, junto con otros principios en quechua y guaraní en el art. 8, en un segundo acápite que podría considerarse como una glosa ampliada de lo mismo, añade:

"II. El Estado se sustenta en los valores de unidad, igualdad, inclusión, dignidad, libertad, solidaridad, reciprocidad, respeto, complementariedad, armonía, transparencia, equilibrio, igualdad de oportunidades, equidad social y de género en la participación, bienestar común, responsabilidad, justicia social, distribución y redistribución de los productos y bienes sociales, para vivir bien." (Art. 8-II)

En el capítulo educativo lo asocia además y principalmente a la relación con la naturaleza, curiosamente, sin una referencia específica a los valores de convivencia social tan centrales en el concepto original suma qamaña y a todo el proceso educativo:

"La educación tendrá estará orientada a la formación individual y colectiva; al desarrollo de competencias, aptitudes y habilidades físicas e intelectuales que vincule la teoría con la práctica productiva; a la conservación y protección del medio ambiente, la biodiversidad y el territorio para el vivir bien". (Art. 80-I)

Finalmente, ya en la Parte IV, dedicada a la estructura económica del Estado, juega más bien con las dos vertientes:

"El modelo económico boliviano es plural y está orientado a mejorar la calidad de vida y el vivir bien de todas las bolivianas y los bolivianos... 
III. La economía plural articula las diferentes formas de organización económica sobre los principios de complementariedad, reciprocidad, solidaridad, redistribución, igualdad, seguridad jurídica, sustentabilidad, equilibrio, justicia y transparencia. La economía social y comunitaria complementará el interés individual con el vivir bien colectivo." (Art. 306)

Y más adelante hace incluso un esfuerzo para establecer objetivos económicos planificables tomando de nuevo en cuenta las diversas dimensiones:

"Para eliminar la pobreza y la exclusión social y económica, para el logro del vivir bien en sus múltiples dimensiones, la organización económica boliviana establece los siguientes propósitos:

1. Generación del producto social en el marco del respeto de los derechos individuales, así como de los derechos de los pueblos y las naciones.

2. La producción, distribución y redistribución justa de la riqueza y de los excedentes económicos.

3. La reducción de las desigualdades de acceso a los recursos productivos.

4. La reducción de las desigualdades regionales.

5. El desarrollo productivo industrializador de los recursos naturales.

6. La participación activa de las economías pública y comunitaria en el aparato productivo." (art. 313).

Inesperadamente, la expresión vivir bien no aparece en toda la Parte III que, junto con la referencia permanente a las "naciones y pueblos indígena campesino originarios" es la innovación más novedosa de toda la Constitución. Sin embargo, está obviamente implícita en todo lo referente a las autonomías "indígena campesino originarias". Veamos, por ejemplo, la definición de los sujetos de esta forma de autonomía:

"La autonomía indígena originaria campesina consiste en el autogobierno como ejercicio de la libre determinación de las naciones y los pueblos indígena originario campesinos, cuya población comparte territorio, cultura, historia, lenguas, y organización o instituciones jurídicas, políticas, sociales y económicas propias" (Art. 289).

Estamos pues ante una expresión sintética que viene a ser una manera más "inculturada" de expresar la nueva utopía de país. Pero queda por delante toda la tarea de vaciarla además en términos más operativos para que en la práctica sí nos vayamos acercando a una sociedad en realmente convivamos bien entre todos nosotros y también con la Madre Tierra que a todos nos cobija.

En toda la CPE boliviana esta frase, debe tomarse no como cinco conceptos sino como una referencia a los pueblos con raices pre-coloniales (art. 2) en la que se juntan las principales palabras las que ellos mismos gustan referirse a sí mismos, según las experiencias y denominaciones históricas por las que han pasado. Ver Romero y Albó (en prensa). 


\section{BIBLIOGRAFÍA}

Albó, Xavier. 1975. La paradoja Aymara: solidaridad y faccionalismo. Cuadernos de Investigación, n. 8. La Paz: Centro de Investigación y Promoción del Campesinado. Albó, Xavier. 2002. Pueblos indios en la política. La Paz: CIPCA.

Bertonio, Ludovico. 1612/1984. Vocabulario de la lengua aymara. Edición facsimilar con Introducción de Xavier Albó y Félix Layme. Cochabamba (Bolivia): CERES, IFEA y MUSEF.

Bolivia. 2009. Constitución Política del Estado. La Paz.

De Lucca, M. 1987. Diccionario Práctico Aymara-Castellano y Castellano-Aymara. La Paz/Cochabamba: Los Amigos del Libro

Layme P., Félix. 2004. Diccionario bilingüe aymara castellano. La Paz: Consejo Educativo Aymara.

Lira, Jorge. 1941/1982. Diccionario Kkechuwa-Español. 2a edición autorizada por el autor. Bogotá: Secretaría Permanente del Convenio "Andrés Bello", Instituto Internacional de Integración, Instituto Andino de Artes Populares.

Medina, Javier. 2001a. La comprensión indígena de la buena vida. La Paz: PADEPGTZ.

Medina, Javier. 2001b. La comprensión guaraní de la buena vida. La Paz: PADEPGTZ.

Medina, Javier. 2002. La vía municipal hacia la buena vida. La Paz: PADEP-GTZ.

Melià, Bartomeu. 1987. La tierra sin mal de los guaraní. Asunción: Suplemento Antropológico.

Temple, Dominique. 2003. Teoría de la reciprocidad. La Paz: PADEP-GTZ. 3 volúmenes. 